\title{
Once a geologist, always a geologist
}

The Big Bang Theory may not classify geology as a science, but John Gilbey* begs to differ, arguing it is 'science plus'

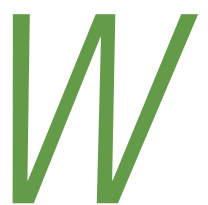

e geologists often spend time walking, looking down, in the open air, in the real world. Understanding what it is that we are standing on is a rare gift not available to everyone or every discipline. Geology requires a unique and open way of thinking.

\section{Transition}

Aged 11, my interests were astronomy, science fiction and dinosaurs. I went on to study geology at university and spent a second-year field position working with Falconbridge Nickel in northern Ontario. Following a spell at the Ghana Geological Survey, I undertook post-graduate research on gold mineralisation in Wales. My interests in mineral exploration were crystallised, my career direction was clear.

Base-metal mineralisation experience in Yorkshire, Australia, The Netherlands, Canada and Guinea gradually led me from geologist to exploration manager to other managerial roles. But, working with teams of very talented geologists in the field and even in head offices ensured that my overriding interest in geology remained. Eventually, I became president of a US corporation mining the largest bauxite deposit in the world, but even this could not eclipse my love of geology. My geological background enhanced my management skills, imparting a clear vision of issues, from all angles, without bias.

\section{Retirement?}

Geologists interests continue and grow.

Reading the article on Earth's Crustal

Thickness (Geoscientist, August 2018)

reminded me once again that I remain hooked.

Following my early retirement from business, I was able to give back to the community in ways that were not possible while living on three continents, five countries and in countless houses and tents, for 23 years. The fundamental nature of a geologist's brain, combined with the approaches learned during years of project management mean there are still useful roles for retired dinosaurs like me.

\section{What to do?}

Professional geology and management are a useful combination of abilities. Using these skills, I've helped teams build facilities from small to very large-tennis pavilions in Toronto and Canterbury, and a flint-walled village hall in Kent, built on time and to budget. I've served as a magistrate and become a councillor and successfully lead council for eight years.

I will remain a geologist with wide geological and non-geological interests. Working in the geosciences creates a network of like-minded friends across the globe. I recently revisited friends in Jackson Hole, Wyoming. We toured the geological wonderland, of Yellowstone and the Tetons, having great conversations on topics from astronomy to algal net development and the provision of free oxygen on our planet! I have excellent debates with my son, who is also a qualified geologist working on base metals and gold exploration.

Regardless of whether you end up as a professional geologist, studying geoscience provides you with transferable skills, a passion for learning and a broad interest in the natural world that lasts a lifetime.

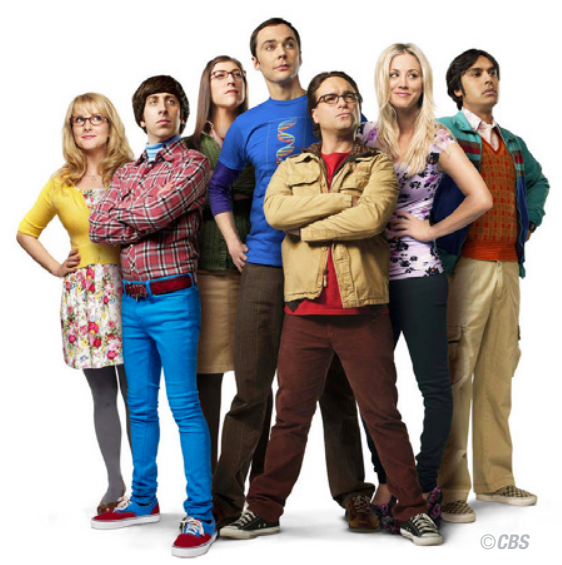

John Gilbey is a retired geologist e-mail: jandcgilbey@gmail.com

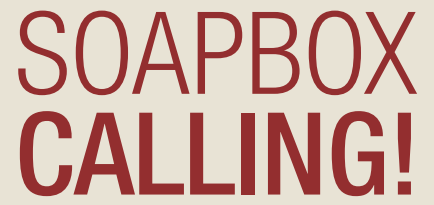

Soapbox is open to contributions from all Fellows. You can always write a letter to the Editor, of

course, but perhaps you feel you need more space?

If you can write it entertainingly in 500 words, the Editor would like to hear from you. Email your piece, and a self-portrait, to amy.whitchurch@geolsoc.org.uk. Copy can only be accepted electronically. No diagrams, tables or other illustrations please.

Pictures should be of print quality - please take photographs on the largest setting on your camera, with a plain background.

Precedence will always be given to more topical contributions. Any one contributor may not appear more often than once per volume (once every 12 months).

STUDYING
GEOSCIENCE
PROVIDES YOU WITH
TRANSFERABLE SKILLS,
A PASSION FOR
LEARNING AND A
BROAD INTEREST IN THE
NATURAL WORLD THAT
LASTS A LIFETIME

JOHN GILBEY 